\title{
Características clínicas y patológicas del cáncer de pulmón
}

\author{
Pedro Luis Ramos Guette, María Athenas Ramos Escalante, Diana Silva
}

Oncológica Oncocare (Bogotá, D.C.)

Introducción: el cáncer de pulmón es la primera causa de incidencia y mortalidad en el mundo. El propósito de este estudio es describir las características clínicas y patológicas de pacientes con cáncer de pulmón y estimar la supervivencia.

Materiales y métodos: se trata de un estudio descriptivo, observacional y retrospectivo de pacientes con cáncer de pulmón durante el período del $1^{\circ}$ de enero de 2013 a marzo de 2016. Se realizaron mediciones descriptivas usando medidas de tendencia central, frecuencias absolutas y relativas. Se estimó la supervivencia por el método de Kaplan-Meier.

Resultados: se identificaron 224 pacientes con una edad promedio de 65 años. Sexo masculino 52\%. El estadio clínico IIIB y IV en el 83\%, estado funcional era ECOG 0-1 en el 58\%. Un 20,3\% presentó metástasis cerebral, el tipo histológico más usual fue adenocarcinoma en un 65,4\% y escamocelular en el $16,8 \%$. Un $12 \%$ tenía EGFR positivo. Régimen subsidiado en un 75\%. Tabaquismo en un $54,46 \%$. La dupleta de quimioterapia de platinos más taxanos se utilizó con más frecuencia $(53,47 \%)$ y también quimioterapia más bevacizumab (17,54\%). Reciben quimioterapia de primera línea en un 64,29\%, mantenimiento en un $19,64 \%$ y quimioterapia de segunda línea en un $15,62 \%$. Presentan tres o más sitios de metástasis en un $41,22 \%$. La mediana de supervivencia global fue de 24,9 meses y la mediana de seguimiento de 30 meses.

Conclusiones: en el cáncer de pulmón el tipo histológico más frecuente es el adenocarcinoma con predominio en el sexo masculino; la quimioterapia más frecuente es dupleta de platinos y hasta un $12 \%$ presenta mutación para el receptor de EGFR. 